\title{
Trends in food insecurity rates at an academic primary care clinic: a retrospective cohort study
}

\author{
Kimberly Montez ${ }^{1 *}$, Callie L. Brown², Arvin Garg 3 , Scott D. Rhodes ${ }^{4}$, Eunyoung Y. Song ${ }^{4,5}$, Alysha J. Taxter ${ }^{1}$,
} Joseph A. Skelton ${ }^{6}$, Laurie W. Albertini ${ }^{1}$ and Deepak Palakshappa ${ }^{7}$

\begin{abstract}
Background: Healthcare organizations are increasingly screening and addressing food insecurity (Fl); yet, limited data exists from clinic-based settings on how FI rates change over time. The objective of this study was to evaluate household FI trends over a two-year period at a clinic that implemented a FI screening and referral program.

Methods: In this retrospective cohort study, data were extracted for all visits at one academic primary care clinic for all children aged 0-18 years whose parents/guardians had been screened for $\mathrm{Fl}$ at least once between February 1 , 2018 to February 28, 2019 (Year 1) and screened at least once between March 1, 2019 to February 28, 2020 (Year 2). Bivariate analyses tested for differences in $\mathrm{Fl}$ and demographics using chi-square tests. Mixed effects logistic regression was used to assess change in Fl between Years 1 and 2 with random intercept for participants controlling for covariates. The interaction between year and all covariates was evaluated to determine differences in Fl change by demographics.
\end{abstract}

Results: Of 6182 patients seen in Year 1, 3691 (59.7\%) were seen at least once in Year 2 and included in this study. In Year 1, 19.6\% of participants reported household Fl, compared to 14.1\% in Year 2. Of those with Fl in Year 1, 40\% had $\mathrm{Fl}$ in Year 2. Of those with food security in Year 1,92.3\% continued with food security in Year 2. Compared to Hispanic/Latinx participants, African American/Black (OR: 3.53, 95\% Cl: 2.33, 5.34; $p<0.001$ ) and White (OR: 1.88, 95\% Cl: 1.06, 3.36; $p=0.03$ ) participants had higher odds of reporting Fl. African American/Black participants had the largest decrease in $\mathrm{Fl}$ between Years 1 and 2 (-7.9, 95\% Cl: - 11.7, - 4.1\%; $p<0.0001)$.

Conclusions: Because Fl is transitional, particularly for racial/ethnic minorities, screening repeatedly can identify families situationally experiencing Fl.

Keywords: Food insecurity, Social determinants of health, Primary care

\section{Background}

Food insecurity (FI), the lack of dependable access to sufficient affordable, nutritious foods for an active and healthy life [1], is a public health dilemma in the United States (US). In 2019, an estimated 35.2 million people in

\footnotetext{
* Correspondence: kmontez@wakehealth.edu

'Department of Pediatrics, Wake Forest University Health Sciences, Winston-Salem, NC 27157, USA

Full list of author information is available at the end of the article
}

the US had FI (10.5\%); households with children disproportionately experienced FI (13.6\%), affecting 10.7 million children nationwide [1]. FI is known to negatively impact child physical, developmental, and mental health outcomes [2,3]. Due to the prevalence and association with negative child health outcomes, both the American Academy of Pediatrics (AAP) recommends that providers routinely screen families for household FI $[4,5]$. Health care institutions, payers, and stakeholders are

(c) The Author(s). 2021 Open Access This article is licensed under a Creative Commons Attribution 4.0 International License, which permits use, sharing, adaptation, distribution and reproduction in any medium or format, as long as you give appropriate credit to the original author(s) and the source, provide a link to the Creative Commons licence, and indicate if changes were made. The images or other third party material in this article are included in the article's Creative Commons licence, unless indicated otherwise in a credit line to the material. If material is not included in the article's Creative Commons licence and your intended use is not permitted by statutory regulation or exceeds the permitted use, you will need to obtain permission directly from the copyright holder. To view a copy of this licence, visit http://creativecommons.org/licenses/by/4.0/ The Creative Commons Public Domain Dedication waiver (http://creativecommons.org/publicdomain/zero/1.0/) applies to the data made available in this article, unless otherwise stated in a credit line to the data. 
increasingly recognizing the importance of screening patients for and addressing FI in clinical settings [6-8].

While there is a growing body of research focused on the process of screening for FI in healthcare settings and referring families for resources, there are still limited data from clinic-based settings on changes in FI rates over time $[9,10]$. FI is often transient, with children and families moving in and out of FI over time due to changes in family circumstances or seasonal fluctuations in food availability due, for example, to changes in household expenses, and availability of school meals [11-13]. However, to date, the majority of studies evaluating programs that screen and address FI in clinical care settings have been cross-sectional [3, 14, 15]. Few studies have demonstrated FI patterns longitudinally among a cohort of pediatric participants in a clinical setting [16].

The objective of this study was to evaluate the trends in FI rates over a two-year period among a cohort of pediatric participants at one urban, academic primary care clinic that had implemented a FI screening and referral program.

\section{Methods}

\section{Study overview and participants}

We conducted a retrospective cohort study of children ages $0-18$ years old within families that were screened for FI between February 1, 2018 and February 28, 2020 at an academic pediatric primary care clinic. This clinic receives approximately 19,000 visits annually, including 11,000 well child visits and 8000 acute care visits, and serves a primarily low-income, urban, Medicaid-insured population. The clinic is located in medium-sized city within Forsyth County, North Carolina and serves a community in which $22.7 \%$ of the population is under 18 years; $27.5 \%$ report being African American/Black, 13.3\% Hispanic/Latinx, and 56.3\% non-Hispanic White; $34 \%$ of persons aged 25 years and older have a Bachelor's degree or higher; and $15.2 \%$ live in poverty [17]. The clinic is the teaching site for the pediatric residency program, including continuity clinics. The clinic is staffed by 15 attending physicians who primarily supervise the residents, 5 of whom directly provide patient care. There are 38 residents who provide care; 16 are first year residents. All providers receive an orientation regarding clinic procedures, including FI screening and referral, as well as periodic FI lectures throughout the year [9].

Beginning in January 2018, the clinic began systematically screening all patients and families with a child presenting for any visit type (including well-child, return, and urgent visits) for household FI using a paper-based form; prior to that, the clinic had been screening verbally since 2014 [9]. The paper-based questionnaire screened patients for several unmet social needs, including housing instability, lack of transportation, utility insecurity, intimate partner violence, and legal problems, and it included the Hunger Vital Sign ${ }^{\mathrm{Tm}}$ (HVS) to screen families for household FI. The HVS was developed for use as a clinical screening measure and has been recommended by the AAP for FI screening at pediatric health supervision visits $[4,18]$. As the pediatric patient was accompanied to an exam room, the nurse provided the parent or guardian with the paper-based questionnaire in English or Spanish depending on the language preference of the parent or guardian. Parents/guardians of children and adolescents completed the questionnaire prior to being seen by the clinician. The results of the written questionnaire were then reviewed by the clinician at the time of the visit, discussed with the family, and entered into the visit documentation template in discreet data fields. The documentation rate for providers was approximately 97\% [9]. Resources available at the time of the visit included (1): a bag of nonperishable food items to feed a family of four for 3-4. meals (2), a list of local community-based hunger relief resources (e.g. food pantries, mobile food programs, etc.) (3), meeting with the clinic's on-site care coordinator to discuss and assist families with obtaining additional community resources (e.g. cooking programs) if the family was interested, and (4) for those meeting with the care coordinator, a follow up phone call, and (5) referrals to federal nutrition programs (e.g. Supplemental Nutrition Assistance Program).

We extracted data from the electronic health record (EHR) for all patients who had been screened for FI at least once between February 1, 2018 to February 28, 2019 (Year 1) and screened at least once between March 1, 2019 to February 28, 2020 (Year 2). Patients were excluded if they were not $0-18$ years of age during Year 1 for a total study population of 3691 children.

\section{Food insecurity}

The HVS screening measure is used by our clinic to screen for household FI at every visit and therefore served as the basis for assessing FI status in this study. The HVS includes two questions: "Within the past 12 months we worried whether our food would run out before we got money to buy more" and "Within the past 12 months, the food we bought just didn't last and we didn't have the money to get more." [18] The validated HVS by Hager et al. uses the answer responses of "often true," "sometimes true," "never true," and "don't know/refused." Our clinic modified the HVS answer choices to binary response options, "yes" or "no." A response of "yes" by the caregiver to either question indicates a positive screen for household FI. Because the HVS asks about FI within the 12 months, a family was considered to 
have FI at least once during Year 1 or FI at least once during Year 2 if they screened positive for FI at any visit during that year. Our outcome of interest was the change in FI over time between Year 1 and Year 2.

\section{Patient demographics}

We extracted demographic data from the EHR for each participant screened, including age (categorized in this analysis as 0 to $<6$ years of age; 6 to $<12$ years of age, $>=12$ years of age), sex, race, and ethnicity. Race/ethnicity was categorized for this analysis as self-identified non-Hispanic White, non-Hispanic African American/Black, Hispanic/Latinx, or other; the other category included self-identification as more than one race. We also extracted the preferred language reported by the caregiver (English, Spanish, or other) and insurance type. Insurance type was categorized as public, private, or self-pay. We also assessed if the caregiver of a participant received any type of resource (e.g. food bag, care coordinator meeting) at any visit during Year 1.

\section{Statistical analyses}

Participant characteristics were presented as $\mathrm{N}$ (percent) for categorical variables. Bivariate analyses tested for differences in patient demographics between participants who were included and participants who were not using chi-square tests. In primary analysis, mixed effects logistic regression was used to assess the change in FI between Year 1 and Year 2 with random intercept for the individual participant and controlling for age, sex, race/ ethnicity, language, and insurance. Because changes in national FI rates have varied based on demographic characteristics, a priori it was hypothesized that there may be differences in the change in FI over time based on the demographic characteristics of participants (age group, sex, race/ethnicity, language, and insurance status) $[1,19]$. In order to evaluate these potential differences, the interaction between the year and all covariates was evaluated to determine if differences in the change in FI varied by participant demographics in secondary analyses. A potential interaction $(p<0.2)$ between year and race/ethnicity was found, and the predicted probability of FI between groups over time was estimated using the margins command in Stata. Two-sided hypothesis test was used, and an alpha $<0.05$ was considered significant. All statistical analyses were conducted using Stata 15.0 (StataCorp, College Station, TX). The Wake Forest School of Medicine Institutional Review Board approved this study for expedited review (\#IRB00062179). This research met the criteria for a waiver of consent entirely according to 45 CFR 46(d).

\section{Results}

Study population characteristics

Of the 6182 patients seen in Year 1, 3691 (59.7\%) were seen at least once in Year 2 and included in this study (Table 1). The 2491 (40.3\%) patients who were not included were significantly more likely to be older age, but there were no significant differences in FI rates or other covariates at baseline. Of the 3691 participants included in this analysis, the majority of their caregivers reported being Hispanic/Latinx (63.8\%), having Medicaid or other public insurance (94\%), and speaking Spanish (55.2\%). About half of participants were less than 6 years of age, $31 \%$ were $6-12$ years, and $20 \%$ were $12-18$ years old. In Year 1, 19.6\% of caregivers reported FI to their pediatric provider, compared to $14.1 \%$ in Year 2.

\section{Change in food insecurity over time}

The change in FI is demonstrated in Fig. 1. Of those who reported food security in Year 1, most (92.3\%) continued to report food security in Year 2. Of the 723 participants' caregivers who identified as having FI in Year 1, 657 (90.9\%) had documentation in the EHR indicating that they had received at least one resource in the clinic at one of their visits during Year 1. Of those who screened positive for FI in Year 1, less than half (40\%) continued to screen positive for FI in Year 2. Caregivers of participants who continued to screen positive for FI in Year 2 were significantly more likely to have received at least one resource in Year 1 than caregivers of participants who had screened positive for FI in Year 1, but then screened negative in Year $2(93.8 \%$ vs $88.9 \%, p=$ 0.02). Among all cohort participants, the majority (75.2\%) of caregivers remained food secure between Year 1 and Year 2, while 6.2\% transitioned from having food security to having $\mathrm{FI}$, and $11.7 \%$ transitioned in the opposite direction.

Between both years, 7.9\% continued to report FI. Between Year 1 and Year 2, we found a decline in the predicted proportion of caregivers who screened positive for FI (Fig. 2).

In mixed effects models controlling for age, sex, race/ ethnicity, language, and insurance status, participants' caregivers had a significantly lower odds of reporting FI in Year 2 compared to Year 1 (OR: 0.56, 95\% CI: 0.48, $0.66 ; p<0.001$ ) (Table 2). Among the study population, families with children who were $6-12$ years of age (OR: 0.74, 95\% CI: $0.57,0.96 ; p=0.02$ ) and greater than 12 years of age (OR: $0.48,95 \%$ CI: $0.36,0.65 ; p<0.001$ ) had a lower odds of reporting FI during the study period compared to families with children between 0 and 6 years of age. Compared to the Hispanic/Latinx group, African American/Black (OR: 3.53, 95\% CI: 2.33, 5.34; $p<0.001$ ), White (OR: 1.88, 95\% CI: 1.06, 3.36; $p=0.03$ ), 
Table 1 Study population baseline demographics

\begin{tabular}{|c|c|c|}
\hline & & Total population: $\mathrm{N}(\%)$ \\
\hline & & 3691 \\
\hline Sex & Female & $1783(48.3)$ \\
\hline & Male & $1908(51.7)$ \\
\hline Age group & 0 to $<6$ years of age & $1790(48.5)$ \\
\hline & 6 to $<12$ years of age & $1145(31.0)$ \\
\hline & 12 to $<19$ years of age & $756(20.5)$ \\
\hline Language & English & $1600(43.4)$ \\
\hline & Spanish & $2036(55.2)$ \\
\hline & Other & $55(1.5)$ \\
\hline Race/Ethnicity & Hispanic/Latinx & $2353(63.8)$ \\
\hline & Af. Am./Black & $770(20.9)$ \\
\hline & White & $190(5.2)$ \\
\hline & Other & $378(10.2)$ \\
\hline Insurance & Medicaid & 3467 (94.0) \\
\hline & Private & $75(2.0)$ \\
\hline & Self-pay & $149(4.0)$ \\
\hline Food insecurity year 1 & Yes & $723(19.6)$ \\
\hline Food insecurity year 2 & Yes & $521(14.1)$ \\
\hline
\end{tabular}

Af. Am. African American

and other racial groups (OR: 2.90, 95\% CI: 1.83, 4.60; $p<0.001)$ had a higher odds of reporting FI.

\section{Change in food insecurity over time by demographics}

In secondary analyses, a potential interaction between race/ethnicity and year was identified, and the predicted probability of FI between groups was determined over time while controlling for all other covariates. We found a significant decrease in the percent of participants' caregivers who reported FI among all racial/ethnic groups (Table 3). African American/Black caregivers were found to have the largest decrease in self-reported FI between Year 1 and Year 2 (-7.9, 95\% CI: $-11.7,-4.1 \%$; $p<$ 0.0001). Caregivers who reported being Hispanic/Latinx were found to have the smallest decrease in selfreported FI between Year 1 and Year 2 (- 1.8, 95\% CI: -

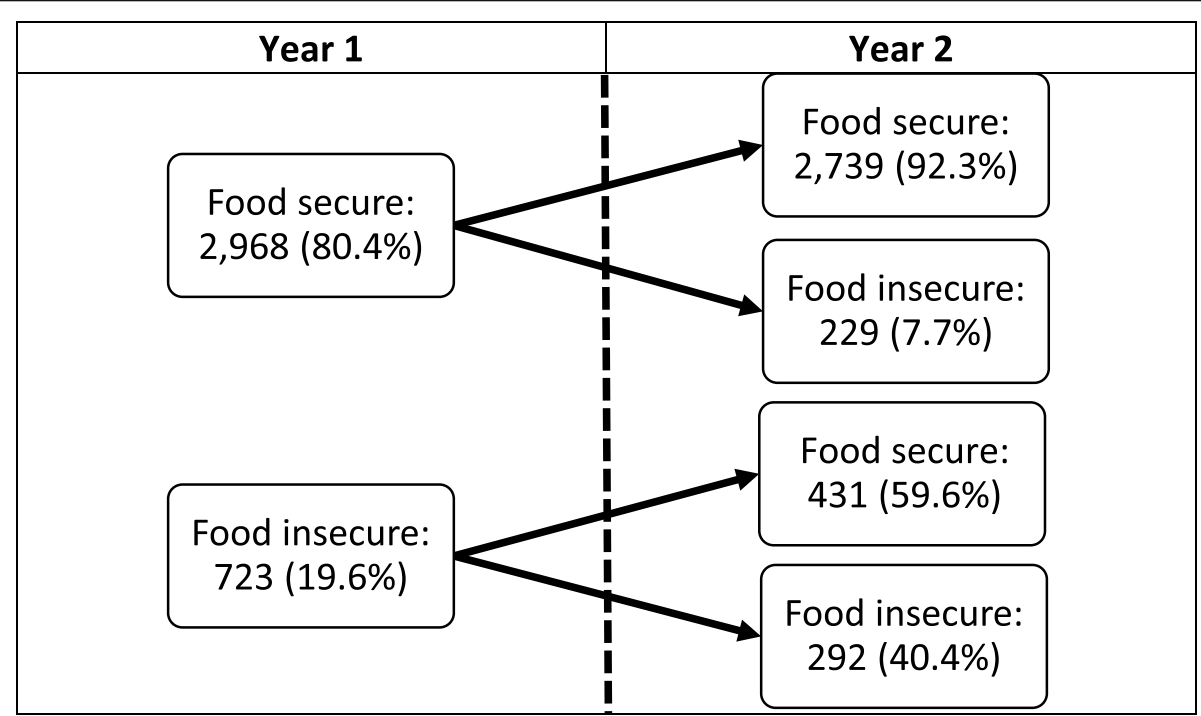

Fig. 1 Change in food insecurity responses over time 


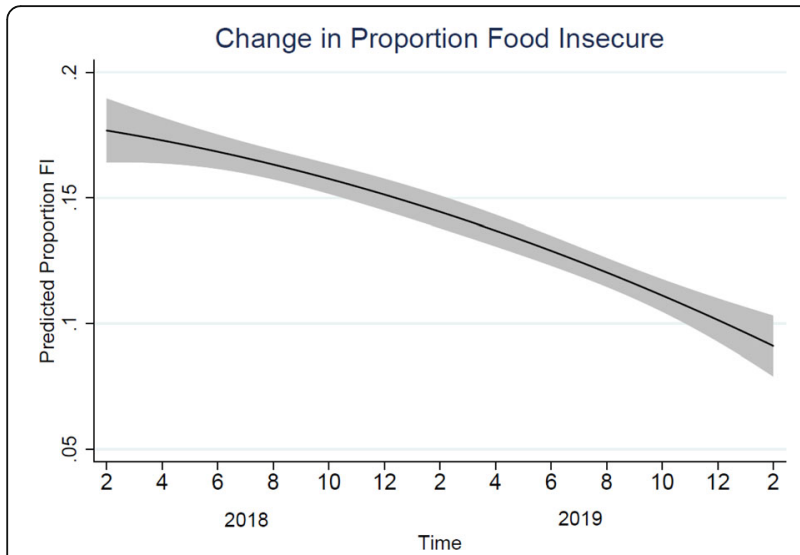

Fig. 2 Change in the predicted proportion of participants reporting food insecurity per month

2.7, $-0.9 \% ; p=0.0001)$. We did not find a potential interaction between year and all other covariates, including age group, sex, language, and insurance status.

\section{Discussion}

Over a two-year period, a statistically significant decline in the proportion of participants who screened positive for FI was demonstrated at one academic pediatric primary care clinic serving primarily Medicaid-insured patients that had implemented a FI screening and referral program. Of those who reported FI in Year 1, less than half continued to report FI in Year 2; the vast majority

Table 2 Multivariable model evaluating odds of reporting food insecurity during the study period

\begin{tabular}{llll}
\hline & & OR $(\mathbf{9 5} \% \mathrm{Cl})$ & $\boldsymbol{p}$-value \\
\hline Year & 1 & Ref & \\
Sex & 2 & $0.56(0.48,0.66)$ & $<\mathbf{0 . 0 0 1}$ \\
& Female & Ref & \\
Age group & Male & $0.91(0.73,1.14)$ & 0.43 \\
& 0 to $<6$ years of age & Ref & \\
& 6 to $<12$ years of age & $0.74(0.57,0.96)$ & $\mathbf{0 . 0 2}$ \\
Language & 12 to $<19$ years of age & $0.48(0.36,0.65)$ & $<\mathbf{0 . 0 0 1}$ \\
& English & Ref & \\
& Spanish & $1.12(0.78,1.61)$ & 0.55 \\
Race/Ethnicity & Other & $0.61(0.23,1.60)$ & 0.31 \\
& Hispanic/Latinx & Ref & \\
& Af. Am./Black & $3.53(2.33,5.34)$ & $<\mathbf{0 . 0 0 1}$ \\
& White & $1.88(1.06,3.36)$ & $\mathbf{0 . 0 3}$ \\
& Other & $2.90(1.83,4.60)$ & $<\mathbf{0 . 0 0 1}$ \\
Insurance & Public & Ref & \\
& Private & $0.22(0.09,0.54)$ & $\mathbf{0 . 0 0 1}$ \\
& Self-pay & $0.92(0.55,1.51)$ & 0.73 \\
\hline Af. & &
\end{tabular}

Af. Am. African American of participants' caregivers who reported having food security in Year 1 continued to report food security in Year 2. There was a significant decrease in self-reported FI between the 2 years among all races/ethnicities, although African American/Black participants had the largest decrease, while Hispanic/Latinx participants were found to have the smallest decrease.

There is growing interest among healthcare organizations in addressing FI in clinical settings [4-8]; yet, to date most studies have been cross-sectional $[3,14,15]$. Our results add to the existing literature by examining the longitudinal trends of FI rates among a large cohort of low-income, racially/ethnically diverse pediatric participants at one academic primary care clinic that had implemented a FI screening and referral program. Overall, prior to the Coronavirus Disease 2019 pandemic (COVID-19), we found a decrease in FI rates between 2 years of a clinic-based FI screening and referral program, with a majority of participants reporting FI transitioning from having FI to having food security (59.6\%). While it remains to be seen how trends will change with COVID19, FI rates are likely to increase, with nationally representative surveys demonstrating record rates among respondents with children [20, 21]. This study's findings are similar to another longitudinal study in a nonclinical setting in which children among a kindergarten cohort undergoing FI screening at two assessments were found to have food security at both assessments (80\%), transition to FI (6\%), and FI at both assessments (7\%); however, in our study, more participants transitioned from having FI to reporting food security, possibly associated with clinic-based FI interventions [13]. Authors of a previous clinic-based longitudinal study found smaller percentages of transitions in FI status and FI persistence among a cohort of pediatric participants aged $0-3$ years who were screened for FI multiple times and provided clinic-based interventions [16]. The majority of our cohort included households with children 6 years of age and older, which are known to be at lower risk of having FI compared to children younger than 6 years of age [1], making transitions to having food security more likely for our older cohort.

There are several potential reasons why we may have seen in a decline in FI rates among the study population. The first possible explanation for this study's finding of a decreased trend in FI rates is that the clinic-based screening and referral program was effective at mitigating FI. In bivariate analysis though, participants who continued to screen positive for FI in Year 2 were significantly more likely to have received at least one resource in Year 1 than participants who had screened positive for FI in Year 1, but then screened negative in Year 2. However, this difference in receiving resources was small. While it is possible that an unaccounted for 
Table 3 Change in predicted proportion of food insecurity by race/ethnicity

\begin{tabular}{lllll}
\hline & Year 1: Predicted \% $\mathbf{9 5 \%} \mathbf{C l})$ & Year 2: Predicted \% $\mathbf{( 9 5 \% ~ C l )}$ & Adjusted percent difference: \% $\mathbf{( 9 5 \% ~ C l )}$ & $\boldsymbol{p}$-value \\
\hline Hispanic/Latinx & $5.2(3.8,6.5)$ & $3.4(2.4,4.3)$ & $-1.8(-2.7,-0.9)$ & 0.0001 \\
African American/Black & $17.5(12.6,22.5)$ & $9.6(6.4,12.9)$ & $-7.9(-11.7,-4.1)$ & $<0.0001$ \\
White & $12.0(5.7,18.3)$ & $4.2(1.4,7.0)$ & $-7.8(-13.5,-2.2)$ & 0.007 \\
Other & $15.0(9.5,20.5)$ & $8.0(4.5,11.5)$ & $-7.0(-11.7,-2.3)$ & 0.004 \\
\hline
\end{tabular}

All analyses were controlling for covariates including age, gender, race/ethnicity, insurance status, and language

outside factors led to the significant decreased trend in FI rates among the study population, we are not aware of any major changes that occurred to the local food system or availability of resources during the time period studied. For example, locally in Forsyth County, FI rates in households with children had also been declining between 2017 (17\%) and 2018 (15.2\%), the most recent year for which local FI data is available [22]. Second, the observed decrease in FI rates is consistent with local and national data prior to the COVID-19 pandemic, which have similarly shown a decrease in FI in recent years. In the US, FI peaked in 2009 with $21.3 \%$ of households with children reporting FI, and in 2018 and 2019 these rates continued to decrease to 13.9 and $13.6 \%$, respectively [1, 23]. Third, during the second year, participants would have been 1 year older, making FI risk lower since households with older children are at lower FI risk [1]. A fourth possibility is that participants stopped admitting to FI on the paper-based survey, either due to survey fatigue, lack of confidence in clinic-based interventions, stigma, or fear of public charge [24-29]. A fifth possible explanation is that, because of the transient nature of $\mathrm{FI}$, the screening occurred during a season or family circumstance in which the family had food security, although the HVS assesses FI over the previous 12month period, which would have accounted for all four seasons.

Interestingly, we found that changes in FI rates over time varied by race/ethnicity. African American/Black participants were found to have the largest decrease in self-reported FI between Years 1 and 2, followed by White patients. Hispanic/Latinx patients were found to have the smallest decrease. National data in recent years prior to the COVID-19 pandemic also demonstrated a significant decrease in FI rates among African American/Black households, while rates in Hispanic/Latinx households with children remained relatively unchanged [1]. One possible explanation for this study's finding is that Hispanic/Latinx households may be less likely to attend medical visits or to admit to FI on surveys, possibly due to uncertainty in the context of "public charge" and/ or fear of deportation, especially if there is mixed immigration status among family members [30, 31]. Studies have shown that children living in immigrant families are less likely to access health care resources or public benefits, even if the qualifying child is a US citizen [28, 32-35].

Despite the strengths of the study, there are several limitations that should be acknowledged. First, because this study was conducted at a single primary care clinic that serves predominantly low-income, Medicaidinsured, and racial/ethnic minority patients, the results may not be generalizable to other clinical settings or pediatric populations. Second, because the self-report of FI status by parents utilized a dichotomous response for the Hunger Vital Sign ${ }^{\text {tu }}$ rather than a Likert scale (never, sometimes true, or often true), which are more sensitive, families with FI may have been missed [36]. Third, because the FI disclosure rates were reliant on results that were documented in the EHR, we cannot be sure that clinicians accurately documented the results in the EHR. However, in our prior study, we found that almost $97 \%$ of providers documented the results of the FI screen after the implementation of our paper-based screening [9]. Fourth, we were unable to examine key determinants of FI due to the limitations of currently available data within the EHR, such as household income, parental age, household size or composition, and participation in nutritional assistance programs. Fifth, because of the limitations of the data available in the EHR, we are unable to determine which particular resources or how many resources families that screened positive for FI received. We were only able to evaluate if patients received any resources. Seventh, we were unable to determine causality of the program since there was no control group.

\section{Conclusions}

Our study contributes to the understanding of longitudinal changes in FI status among a cohort of pediatric participants in a clinical setting following implementation of a FI screening and referral program. Our findings add to the current body of knowledge that FI is often transitional, reinforcing the importance of longitudinal screening for household FI in the primary care setting, particularly for racial/ethnic minorities. Screening repeatedly can identify families that situationally experience household FI. Further research is needed to determine which interventions are most effective at mitigating FI in a primary care setting. 


\section{Abbreviations}

AAP: Academy of Pediatrics; COVID-19: Coronavirus Disease 2019; EHR: electronic health record; Fl: food insecurity; HVS: Hunger Vital Sign ${ }^{\mathrm{TM}}$; US: United States

\section{Acknowledgements}

The authors gratefully acknowledge the data extraction services of the Wake Forest Clinical and Translational Science Institute.

\section{Authors' contributions}

KM conceptualized and designed the study, acquired and interpreted data, drafted portions of the manuscript, and reviewed and revised the manuscript. CLB interpreted data, drafted portions of the manuscript, and reviewed and revised the manuscript. AG conceptualized and designed the study, interpreted data, and substantively revised the manuscript. SDR conceptualized and designed the study, interpreted the data, and substantively revised the manuscript. ES designed the study, analyzed and interpreted data, and substantively revised the manuscript. AJT created electronic health record software to acquire the data, interpreted data, and substantively revised the manuscript. JAS interpreted data and substantively revised the manuscript. LWA interpreted data and substantively revised the manuscript. DP conceptualized and designed the study, acquired, analyzed and interpreted data, drafted portions of the manuscript, prepared figures and tables, and reviewed and revised the manuscript. All authors agreed to be personally accountable for the author's own contributions and to ensure that questions related to the accuracy or integrity of any part of the work, even ones in which the author was not personally involved, are properly investigated, resolved, and the resolution is documented in the literature. All authors approved the final manuscript as submitted.

\section{Funding}

This study was supported by the Kate B. Reynolds Charitable Trust. The Wake Forest Clinical and Translational Science Institute is supported by the National Center for Advancing Translational Sciences (NCATS), National Institutes of Health, through Grant Award Number UL1TR001420. Dr. Brown is supported by a grant from the National Institute of Child Health and Human Development of the National Institutes of Health under Award Number 1K23HD099249. DrGarg is supported by a grant from the National Institute of Child Health and Human Development of the National Institutes of Health under Award Number 5R01HD090191-03. Dr. Rhodes is supported by the National Institute of Nursing Research of the National Institutes of Health under Award Number R01NR019512-01. Dr. Skelton is supported by the National Institute of Nursing Research of the National Institutes of Health under Award Number 5R01NR017639-02. Dr. Palakshappa is supported by the National Heart, Lung, and Blood Institute of the National Institutes of Health under Award Number K23HL146902. The content is solely the responsibility of the authors and does not necessarily represent the official views of the National Institutes of Health. The funding sources had no role in the design and conduct of the study; collection, management, analysis, and interpretation of the data; preparation, review, or approval of the manuscript; and decision to submit the manuscript for publication.

\section{Availability of data and materials}

The data that support the findings of this study are not openly available due to them containing information that could compromise research participant privacy/consent and a data sharing mandate; data are available from the corresponding author [KM] upon reasonable request.

\section{Declarations}

\section{Ethics approval and consent to participate}

The Wake Forest School of Medicine Institutional Review Board approved this study for expedited review (\#IRB00062179). This research met the criteria for a waiver of consent entirely according to 45 CFR 46(d). All methods were carried out in accordance with relevant guidelines and regulations.

\section{Consent for publication}

Not applicable.

\section{Competing interests}

The authors declare that they have no competing interests.

\section{Author details}

'Department of Pediatrics, Wake Forest University Health Sciences, Winston-Salem, NC 27157, USA. ²Departments of Pediatrics and Epidemiology and Prevention, Wake Forest University Health Sciences, Winston-Salem, NC 27157, USA. ${ }^{3}$ Department of Pediatrics, University of Massachusetts Medical School, Worcester, MA 01655, USA. ${ }^{4}$ Department of Social Sciences and Health Policy, Wake Forest University Health Sciences, Winston-Salem, NC 27101, USA. ${ }^{5}$ Health Quality Partners, Doyleston, PA, USA. ${ }^{6}$ Departments of Pediatrics and Epidemiology and Prevention, Wake Forest University Health Sciences, Winston-Salem, NC 27101, USA. ${ }^{7}$ Departments of Pediatrics and Internal Medicine, Wake Forest University Health Sciences, Winston-Salem, NC 27157, USA.

Received: 25 March 2021 Accepted: 7 August 2021

Published online: 27 August 2021

\section{References}

1. Coleman-Jensen A, Rabbitt MP, Gregory CA, Singh A. Household food security in the United States in 2019. Washington, DC: US Department of Agriculture, Economic Research Service; 2020.

2. Shankar P, Chung R, Frank DA. Association of Food Insecurity with Children's behavioral, emotional, and academic outcomes: a systematic review. J Dev Behav Pediatr. 2017;38(2):135-50. https://doi.org/10.1097/DBP. 0000000000000383.

3. Thomas MMC, Miller DP, Morrissey TW. Food insecurity and child health. Pediatrics. 2019:144(4):e20190397.

4. Council on Community Pediatrics, Committee on Nutrition. Promoting food security for all children. Pediatrics. 2015;136(5):e1431-8. https://doi.org/10.1 542/peds.2015-3301.

5. Academic Pediatrics Association Task Force on Childhood Poverty. APA Task Force on Childhood Poverty: A Strategic Road Map. MacLean: Academic Pediatric Association; 2013

6. National Academies of Sciences Egnineering and Medicine. Integrating Social Care into the Delivery of Health Care: Moving Upstream to Improve the Nation's Health. Washington, DC: The National Academies Press; 2019.

7. Phelps M, Phillips LLP. Medicaid's Role in Addressing Social Determinants of Health. Princeton: Robert Wood Johnson Foundation; 2019.

8. Alley DE, Asomugha CN, Conway PH, Sanghavi DM. Accountable health communities - Adressing social needs through Medicare and Medicaid. N Engl J Med. 2016;374(1):8-11. https://doi.org/10.1056/ NEJMp1512532.

9. Palakshappa D, Goodpasture M, Albertini L, Brown CL, Montez K, Skelton JA. Written versus verbal food insecurity screening in one primary care clinic. Acad Pediatr. 2019:20:203-7.

10. Bottino CJ, Rhodes ET, Kreatsoulas C, Cox JE, Fleegler EW. Food insecurity screening in pediatric primary care: can offering referrals help identify families in need? Acad Pediatr. 2017;17(5):497-503. https://doi.org/10.1016/ j.acap.2016.10.006.

11. Loopstra R, Tarasuk V. Severity of household food insecurity is sensitive to change in household income and employment status among low-income families. J Nutr. 2013;143(8):1316-23. https://doi.org/10.3945/jn.113.175414.

12. Huang J, Kim Y, Barnidge E. Seasonal difference in National School Lunch Program Participation and its impacts on household food security. Health Soc Work. 2016;41(4):235-43. https://doi.org/10.1093/hsw/hlw043.

13. Kimbro RT, Denney JT. Transitions into food insecurity associated with behavioral problems and worse overall health among children. Health Aff. 2015;34(11):1949-55. https://doi.org/10.1377/hlthaff.2015.0626.

14. Johnson AD, Markowitz AJ. Food insecurity and family well-being outcomes among households with young children. J Pediatr. 2018;196:275-82. https:// doi.org/10.1016/j.jpeds.2018.01.026.

15. Peltz A, Garg A. Food insecurity and health care use. Pediatrics. 2019;144(4): e20190397.

16. Courts KA, Hubbard RA, Kersten HB, Klusaritz H. Stability of food insecurity status in paediatric primary care. Public Health Nutr. 2020:24:1-6.

17. United States Census Bureau. Quick Facts. Forsyth County: US Census Bureau; 2019. Available from: https://www.census.gov/quickfacts/ forsythcountynorthcarolina

18. Hager ER, Quigg AM, Black MM, Coleman SM, Heeren T, Rose-Jacobs R, et al. Development and validity of a 2-item screen to identify families at risk for food insecurity. Pediatrics. 2010;126(1):e26-32. https://doi.org/10.1542/peds.2 009-3146. 
19. Balistreri KS. A decade of change: measuring the extent, depth and severity of food insecurity. J Fam Econ Issues. 2016;37(3):373-82. https://doi.org/10.1 007/s10834-016-9500-9.

20. Schanzenbach D, Pitts A. Estimates of food insecurity during the COVID-19 crisis: results from the COVID impact survey, week 2 (may 4-10, 2020). Chicago: Institute for Policy Research Nortwestern University; 2020.

21. Bauer L. The COVID-19 crisis has already left too many children hungry in America. Washington, DC: The Hamilton Project; 2020. Available from: https://www.hamiltonproject.org/blog/the_covid_19_crisis_has_already_ left_too_many_children_hungry_in_america

22. Feeding America. Map the meal gap. Chicago: Feeding America; 2018 updated 2019. Available from: https://map.feedingamerica.org/county/2018/ overall/north-carolina/county/forsyth.

23. Coleman-Jensen A, Rabbitt MP, Gregory CA, Singh A. Household food security in the United States in 2018. Washington, DC: US Department of Agriculture, Economic Research Service; 2019.

24. Finch AJJ, Saylor CF, Edwards GL, McIntosh JA. Children's depression inventory: reliability over repeated administrations. J Clin Child Psychol. 1987;16(4):339-41. https://doi.org/10.1207/s15374424jccp1604_7.

25. Perrin EC. Ethical questions about screening. J Dev Behav Pediatr. 1998; 19(5):350-2. https://doi.org/10.1097/00004703-199810000-00006.

26. Gaines-Turner T, Simmons JC, Chilton M. Recommendations from SNAP participants to improve wages and end stigma. Am J Public Health. 2019; 109(12):1664-7. https://doi.org/10.2105/A.JPH.2019.305362.

27. Cullen D, Blauch A, Mirth M, Fein J. Complete eats: summer meals offered by the emergency department for food insecurity. Pediatrics. 2019;144(4): e20190397.

28. Pelto DJ, Ocampo A, Garduno-Ortega O, Barraza Lopez CT, Macaluso F. Ramirez J, et al. The nutrition benefits participation gap: barriers to uptake of SNAP and WIC among Latinx American immigrant families. J Community Health. 2020;45(3):488-91. https://doi.org/10.1007/s10900-019-00765-z.

29. Sommers BD, Allen H, Bhanja A, Blendon RJ, Orav EJ, Epstein AM. Assessment of perceptions of the public charge rule among low-income adults in Texas. JAMA Netw Open. 2020;3(7):e2010391. https://doi.org/10.1 001/jamanetworkopen.2020.10391.

30. Bleich SN, Fleischhacker S. Hunger or deportation: implications of the trump Administration's proposed public charge rule. J Nutr Educ Behav. 2019;51(4): 505-9. https://doi.org/10.1016/j.jneb.2019.01.019.

31. Raphael JL, Beers LS, Perrin JM, Garg A. Public charge: an expanding challenge to child health care policy. Acad Pediatr. 2020;20(1):6-8. https:// doi.org/10.1016/j.acap.2019.09.001.

32. Toomey RB, Umana-Taylor AJ, Williams DR, Harvey-Mendoza E, Jahromi LB, Updegraff KA. Impact of Arizona's SB 1070 immigration law on utilization of health care and public assistance among Mexican-origin adolescent mothers and their mother figures. Am J Public Health. 2014;104(Suppl 1): S28-34. https://doi.org/10.2105/AJPH.2013.301655.

33. Vargas ED, Pirog MA. Mixed-status families and Wic uptake: the effects of risk of deportation on program use. Soc Sci Q. 2016;97(3):555-72. https:// doi.org/10.1111/ssqu. 12286 .

34. Zallman L, Finnegan KE, Himmelstein DU, Touw S, Woolhandler S. Implications of changing public charge immigration rules for children who need medical care. JAMA Pediatr. 2019;173:e191744.

35. Tang MN, Ettinger de Cuba S, Coleman SM, Heeren T, Sandel M, Chilton M, et al. Maternal place of birth, socioeconomic characteristics, and child health in US-born Latinx children in Boston. Acad Pediatr. 2020;20(2):225-33. https://doi.org/10.1016/j.acap.2019.09.005.

36. Makelarski JA, Abramsohn E, Benjamin JH, Du S, Lindau ST. Diagnostic accuracy of two food insecurity screeners recommended for use in health care settings. Am J Public Health. 2017;107(11):1812-7. https://doi.org/10.21 05/AJPH.2017.304033.

\section{Publisher's Note}

Springer Nature remains neutral with regard to jurisdictional claims in published maps and institutional affiliations.

Ready to submit your research? Choose BMC and benefit from:

- fast, convenient online submission

- thorough peer review by experienced researchers in your field

- rapid publication on acceptance

- support for research data, including large and complex data types

- gold Open Access which fosters wider collaboration and increased citations

- maximum visibility for your research: over $100 \mathrm{M}$ website views per year

At BMC, research is always in progress.

Learn more biomedcentral.com/submissions 